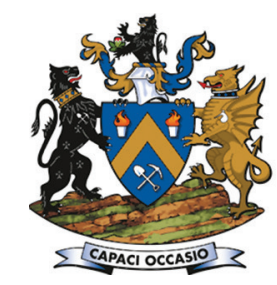

Affiliation:

1DSI/NRF Clean Coal Technology Research Group, School of Chemical and Metallurgy, Faculty of Engineering and the Built Environment, University of the Witwatersrand, South Africa.

Correspondence to:

S.0. Bada

Email:

Samson.Bada@wits.ac.za

Dates:

Received: 5 Dec. 2021

Revised: 20 Sep. 2021

Accepted: 20 0ct. 2021

Published: December 2021

How to cite:

Setsepu, R.L, Abdulsalam, J., and

Bada, S.0. 2021

Effects of Searsia lancea hydrochar

inclusion on the mechanical

properties of hydrochar/discard

coal pellets.

Journal of the Southern African

Institute of Mining and Metallurgy,

vol. 121, no. 12, pp. $617-622$

DOI ID:

http://dx.doi.org/10.17159/2411-

9717/1449/2021

ORCID:

R.L Setsepu

https://orcid.org/0000-0002-

1682-478X

J. Abdulsalam

https://orcid.org/0000-0001-

5072-4996

S.O. Bada

https://orcid.org/0000-0002-

1079-3492

\section{Effects of Searsia lancea hydrochar inclusion on the mechanical properties of hydrochar/discard coal pellets}

\author{
by R.L Setsepu ${ }^{1}$, J. Abdulsalam ${ }^{1}$, and S.O. Bada ${ }^{1}$
}

\section{Synopsis}

The utilization of biomass as a solid fuel for co-firing has received great attention from boiler manufacturers as a clean coal technology (CCT) option. This research aimed to produce biocoal pellets, as a clean energy fuel, using hydrochar from trees planted to rehabilitate acid mine drainage (AMD) water and fine coal discards. The hydrochar was synthesized by hydrothermal carbonization of Searsia lancea harvested from AMD-contaminated land at a temperature of $280^{\circ} \mathrm{C}$ and a residence time of 90 minutes. It was blended with discard coal $(-1 \mathrm{~mm})$ at ratios of $25 \%$ and $50 \%$ hydrochar to produce different forms of solid pelletized biocoal (BC). The physicochemical and mechanical properties of each of the biocoal pellet blends were determined. The $100 \%$ hydrochar had the highest calorific value of 29.99 $\mathrm{MJ} / \mathrm{kg}$, while the raw discard coal had a calorific value of $16.73 \mathrm{MJ} / \mathrm{kg}$. The ash content decreased from $42 \%$ in the discard coal to $25 \%$ in the blend of $50 \%$ coal and $50 \%$ hydrochar biocoal pellets. Biocoal pellets comprising $25 \%$ hydrochar and $75 \%$ discard coal $\left(\mathrm{BC}_{25 \mathrm{HC} / 75 \mathrm{COAL}}\right)$ displayed the best mechanical properties (compressive strength $3.06 \mathrm{MPa}$ ) of all the fuels, but the physicochemical properties were inferior to the $\mathrm{BC}_{50 \mathrm{HC} / 50} \mathrm{COAL}$ pellets. This research has demonstrated that hydrochar synthesized from a tree species planted for hydraulic control of AMD has the capability to act as a binder for improving the mechanical properties and energy characteristics of fine discard coal.

\section{Keywords}

acid mine drainwwage, co-fired feedstock, discard coal, hydrochar, hydrothermal carbonization, pellets, Searsia lancea.

\section{Introduction}

The world population in 2017 was estimated to be around 7.3 billion and is projected to increase to 10.5 billion by the year 2040 (EIA, 2016; Saba, Sha, and Reza, 2017). Security of global energy supply is an absolute necessity for sustaining modern life because of the increasing demographic and socioeconomic needs of developing countries. The increase in human population will inevitably require an increase in energy production, necessitating more fossil fuels and biomass to be added to the global energy mix.

The South African energy landscape is still largely based on fossil fuel. That is, the economy still relies heavily on coal for power generation, and its contribution to the total South Africa's energy mix is expected to be 59\% till 2030 (Department of Energy, 2018). However, there is a public outcry regarding the increasing emissions from some of the power plants in the country, which are due to the poorer quality of the coal being utilized. Since South Africa is now obliged to use its remaining low-grade coal, the use of biomass as a clean co-fired fuel is an attractive option for use in these power plants in order to meet the stipulated emission standards. The utilization of biomass and refuse-derived fuels (RDF) for co-firing has received great attention from researchers and boiler manufacturers as a clean coal technology (CCT) option worldwide (Rousset et al, 2011; Kerina, and Bada 2020). Such products are seen as potential alternative renewable energy sources for electricity generation, with low emissions and low ash contents among other beneficial fuel characteristics (Teixeira et al, 2012; Ndou, Bada, and Falcon, 2020).

The continued use of coal depends primarily on (i) advances in CCT with specific respect to the reduction in greenhouse gases (GHG), as well as (ii) answers to allied factors such as the use of coal discard and refuse dumps, low water usage, and management of acid mine drainage (AMD). Gaqa and Watts, (2018) reported that at present, South African energy and liquid fuels are produced primarily from bituminous coal; however, the quality of coals for these applications is rapidly deteriorating and no plan is in place for the use of the abundant discard coal available in the country. Nearly $100 \%$ of the fines 


\section{Effects of Searsia lancea hydrochar inclusion on the mechanical properties}

generated during mining and beneficiation discards from washing plants) is stored in long-term dumps (Bada et al., 2016). Well over 2 billion tons of discarded coal of various grades has accumulated in South Africa due to the lack of practical and feasible methods to use this resource, either as sole products or as co-fired fuel in existing power plants. This research seeks to demonstrate that pelletized hydrochar-infused biocoal ('hydrochar/coal blend') can be produced as a new solid fuel for use in existing coal-fired power plants.

In this study, a new solid pelletized fuel was produced by mixing different parts from Searsia lancea, a Southern African indigenous semi-hardwood tree, and fine discard coal. Searsia lancea is one of the tree species planted in the woodlands project for phytoremediation and control of groundwater pollution from gold and uranium mine tailings dams in southern Africa (Weiersbye, 2007; Botha and Weiersbye, 2010). The woodlands project is part of a mine closure plan for the control of AMD, but there was concern regarding the harvesting of these trees after maturity as firewood by the community. This would undermine the potential of these trees as an alternative energy source. A recent study (Ndou et al., 2020) has demonstrated that Searsia lancea and discard coal could be co-fired. The authors showed that the raw Searsia lancea biomass has a higher combustible reactivity than coal, and the addition of Tamarix usneoides biomass to coal resulted in reduced $\mathrm{NO}_{\mathrm{x}}$ and $\mathrm{CO}_{2}$ emissions.

In the current project, further investigations were undertaken through the process of hydrothermal carbonization (HTC) of this tree species. The aim was to improve the energy content of this biomaterial by producing pellets containing different ratios of hydrochar and biocoal. According to previous reports, HTC enhances the plasticity of biomass (Kudo et al., 2014) and promotes particle coalescence or fusion during the briquetting of such biomass. The process has also been found to remove highly volatile cellulosic material, i.e. cellulose and hemicellulose, thereby converting the biomass into a solid that is composed mainly of lignin (Kudo et al., 2014). The lignin present in the raw biomass can be recovered and used as the binder for different hydrochar and fine coal pellet products. In this investigation, Searsia lancea was used as the HTC binder for pelletizing typical high-inertinite, low-grade South African fine coal, and the physiochemical and mechanical properties of the pellets were assessed.

\section{Materials and methods}

\section{Materials and sample preparation}

The biomass utilized in this study was obtained from Searsia lancea trees planted in 2003 and 2004 for phytoremediation trials on a groundwater-polluted gold and uranium tailings dam at the AngloGold Ashanti Limited West Wits and Vaal River mine in South Africa. The biomass materials from Searsia lancea (trees S11 and S12) included leaves, twigs, wood, dead wood, stump, root ball (coarse root), and root (fine-medium root). The different materials were milled in a Retsch SM 200 mill to $-1 \mathrm{~mm}$ and $-212 \mu \mathrm{m}$ size fractions. The $-1 \mathrm{~mm}$ fractions were subjected to hydrothermal carbonization while the $-212 \mu \mathrm{m}$ fractions were analysed for physicochemical characterization. The combination of tree sections from two trees (S11 and S12) from the same trial site for producing hydrochar was based on the ash content of the individual compartments.. The coal used was fine coal discard obtained from a coalfield in the Mpumalanga Highveld.

\section{Analytical techniques}

Proximate analyses were conducted on all samples in accordance with ASTM D-5142, with approximately $1 \mathrm{~g}$ used for determining the inherent moisture, ash content, and volatile matter present. The fixed carbon content for all samples is expressed as 100\% (ash content + volatile matter + moisture content). The calorific value was determined on all samples using a Leco AC 500 calorimeter in accordance with ASTM D5865-04.

\section{Hydrochar production and pelletization}

Hydrochars were produced in a laboratory-scale high-pressure stirred Berghof BR-1500 reactor. For each experiment, $100 \mathrm{~g}$ of air-dried biomass was mixed with $800 \mathrm{ml}$ of deionized water and fed into the stainless-steel vessel. The vessel contents were then purged using argon gas at an initial pressure of 20 bar for each run, followed by agitation of the mixture at $200 \mathrm{r} / \mathrm{min}$ for the full length of the test. After each test, the hydrochar slurry was filtered and oven-dried at $105^{\circ} \mathrm{C}$ for 24 hours, and then stored in plastic containers for characterization tests. The BC pellets were produced by blending hydrochar and discard coal at ratios of $25 \%$ to $75 \%$ and $50 \%$ to $50 \%$. The samples were mixed using a Kenwood type KVL40 (Chef XL) mixer. The mixer was first run empty, then the hydrochar was slowly added. This was done to break up the lumps that formed during the drying stages of hydrochar formation. After the hydrochar lumps had disintegrated, the required amount of discard coal fines was added and the mixture was then blended for five minutes. The blended samples were formed into pellets using a Specac manual hydraulic laboratory pellet press. All the pellets produced at the two different blending ratios were subjected to proximate analysis, calorific value, and various mechanical tests. The results obtained from the combustion and chemical elemental composition of the pellet samples were reported previously (Setsepu et al., 2021).

\section{Compressive resistance}

The compressive resistance of the pellets was determined following ISO 4700:2007 (E), which stipulates a method that measures the compressive load attained before breakage of the pellets. A load cell of $1000 \mathrm{~N}$ was used as the maximum load for the crushing of the pellets. Initially, the pellets were placed flat onto the crushing surface of the compression machine and the load cell applied. However, it was found that this method simply densified the pellets rather than crushing them. Hence, all pellets tested in the study were placed on the side and subjected to the crushing force while aligned. The compressive strength of the pellet was calculated using Equation $[1]$ :

$$
\sigma=\frac{2 F}{\pi d l}
$$

where $F$ represents the maximum compressive force, $d$ and $l$ represent the diameter and length of the pellet respectively, and $\sigma$ is the compressive strength.

\section{Impact resistance index}

The drop durability method employed in this study is a slight variation on that used by Kambo and Dutta, (2014), who applied the impact resistance test to densified and pre-treated Miscanthus feedstock. In this study, the drop durability of the samples was determined by first taking the mass of each pellet, then dropping it onto a steel plate from a height of $1.0 \mathrm{~m}$, and then weighing the resulting pellet. The impact resistance index (IRI) was calculated according to Equation [2]. 


\section{Effects of Searsia lancea hydrochar inclusion on the mechanical properties}

\author{
$\%$ weight loss $=$ \\ $\left(\frac{\text { Initial mass }- \text { Final mass after } 10 \text { drops }}{\text { Initial mass }}\right) \times 100$
}

\section{Water resistance index}

The moisture uptake or water resistance index was determined by submerging the pellet in a $200 \mathrm{ml}$ container filled with tap water. The pellet was weighed and the mass recorded as the initial mass. The pellet was then placed inside a metal basket which was immersed in tap water for 30 minutes. At the end of the submersion period, the pellet was removed and placed on a paper towel to air out the surface moisture for 2 minutes before taking the final mass. The moisture uptake was determined according to Equation [3]:

$$
\begin{aligned}
& \% \text { Moisture Uptake }= \\
& \left(\frac{\text { Final mass-Initial mass }}{\text { Initial mass }}\right) \times 100
\end{aligned}
$$

After the moisture uptake test was completed, a water resistance index (Equation [4] was determined using the results from Equation [3] as follows:

$$
\begin{aligned}
& W R I=100- \\
& \text { Mass } \% \text { of water after } 30 \text { minutes }
\end{aligned}
$$

According to Richards (1990), a WRI greater than 95\% should be obtained after 30 minutes. This figure is used as the standard for comparisons.

\section{Results and discussion}

\section{Physicochemical characterization}

The proximate analyses and calorific value results obtained from the discard coal, hydrochar, and biocoal pellets are presented in Figure 1. The discard coal had an ash content of about $42 \%$. This high percentage is due to the inorganic minerals in the coal reporting to this fraction after beneficiation, with the clean fraction composed of the organic component. The increase in the percentage of incombustible minerals in the biocoal will lead to a delay in the ignition of the product and reduce its quality. The biocoals made from the blend of 50\% hydrochar and 50\% coal are denoted as $\left(\mathrm{BC}_{50 \mathrm{HC} / 50 \mathrm{C}}\right)$, whereas the $25 \%$ hydrochar and $75 \% \mathrm{coal}$

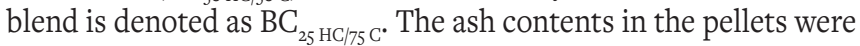
found to be considerably lower than that of the discard coal, being
$35 \%$ and $25 \%$ respectively for $\mathrm{BC}_{25 \mathrm{HC} / 75 \mathrm{C}}$ and $\mathrm{BC}_{50 \mathrm{HC} / 50 \mathrm{C}}$ pellets. The 100\% hydrochar possessed the lowest ash content (3\%) and the highest total moisture (10\%), as expected. Furthermore, as the percentage of the hydrochar in the blend increased, fixed carbon also increased; with the $100 \%$ hydrochar having the highest fixed carbon content because of the sample's almost pure, coal-derived carbon-rich nature. As has been shown by Bada et al. (2018) and Zhu et al. (2018), thermal treatment and HC of plant-derived biomass results in the restructuring, modification, and concentration of the aromatic carbon molecules, thereby increasing the fixed carbon and calorific values of the heat-treated hydrocarbon products.

Regarding the commercial value of the products, an increase in the percentage of hydrochar added to discard fine coal resulted in an increase in the product's commercial grade. The pure discard fine coal is categorized as commercial Grade D3 with a calorific value of $16.73 \mathrm{MJ} / \mathrm{kg}$, whereas the hydrochar presents with a calorific value of over $29 \mathrm{MJ} / \mathrm{kg}$. By increasing the hydrochar proportion in the mix to $50 \%$, the pellet's grade increases to commercial Grade C (25.5 to $26.5 \mathrm{MJ} / \mathrm{kg}$ for the $\mathrm{BC}_{50 \mathrm{HC} / 50 \mathrm{C} \text { pellets. }}$ In accordance with the South African coal classification standard, solid fuels with calorific values of over $28.5 \mathrm{MJ} / \mathrm{kg}$ are considered to have the highest heating value and are classified in a category known as Special Grade Coal.

\section{Mechanical properties}

Effect of hydrochar inclusion on compression strength of pellets

The results obtained from the compression strength tests carried out on the pellets made from the 100\% discard coal, 100\% hydrochar, and coal/hydrochar blends at two different ratios are depicted in Figure 2. The compression strength denotes the maximum strength a pellet can withstand before shattering or disintegrating and provides an indication of the bonding strength between the hydrochar and the coal.

The hydrochar produced at $280^{\circ} \mathrm{C}$ at a residence time of 90 minutes with a biomass-to-water ratio of 1:8 was utilized in the strength tests. Pellets of $2 \mathrm{~g}$ were produced from each sample using a $20 \mathrm{~mm}$ die, with a higher volume of hydrochar required to meet the $2 \mathrm{~g}$ requirement in the $100 \%$ hydrochar sample and the blended samples. The $\mathrm{BC}_{25 \mathrm{HC} / 75 \mathrm{C}}$ sample was found to exhibit the highest compressive strength of $3.06 \mathrm{MPa}$, and the $\mathrm{BC}_{50 \mathrm{HC} / 50 \mathrm{C}}$ pellets a slightly lower compressive strength of 2.67 MPa. Both the 100\% hydrochar and the discard fine coal pellets were found to have lower compressive strengths (1.71 MPa

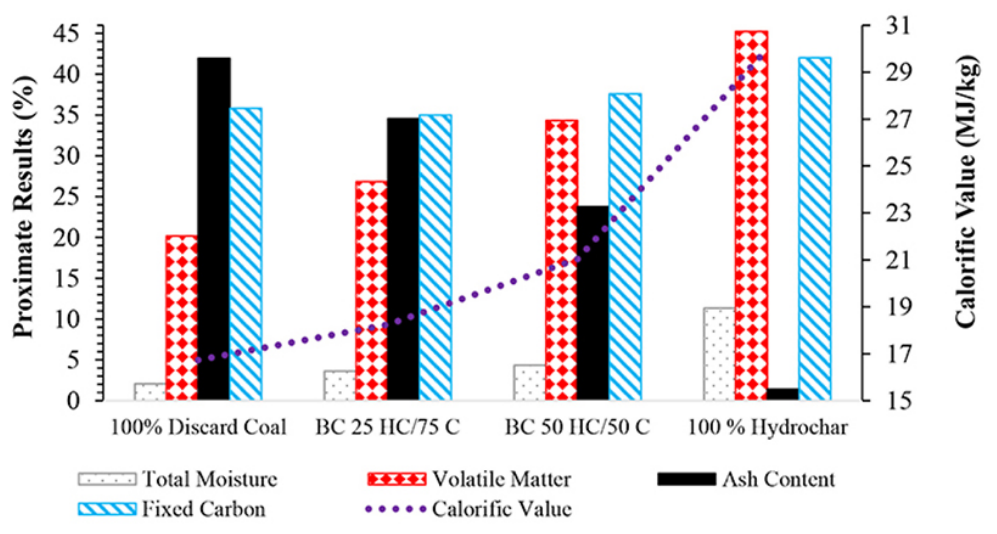

Figure 1-Physicochemical analysis results and calorific values of the discard coal, biocoal blends, and hydrochar 


\section{Effects of Searsia lancea hydrochar inclusion on the mechanical properties}

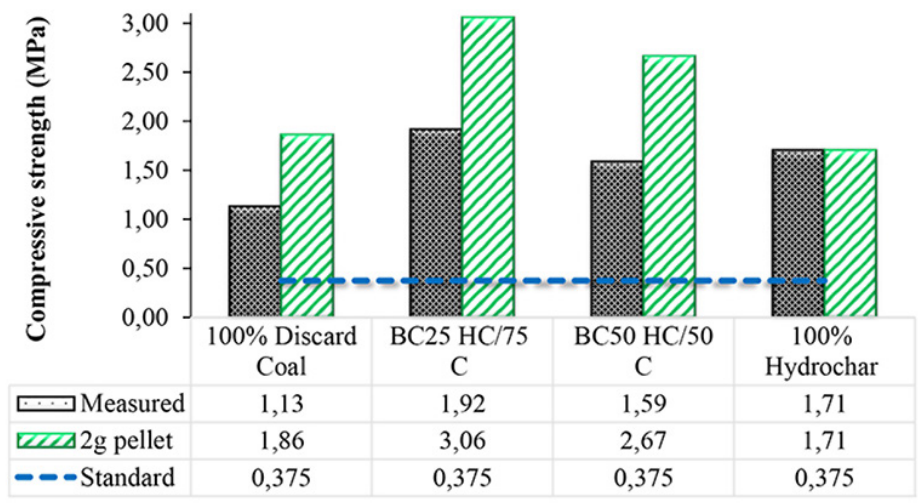

Figure 2-Effect of hydrochar inclusion on the compression strength of pellets

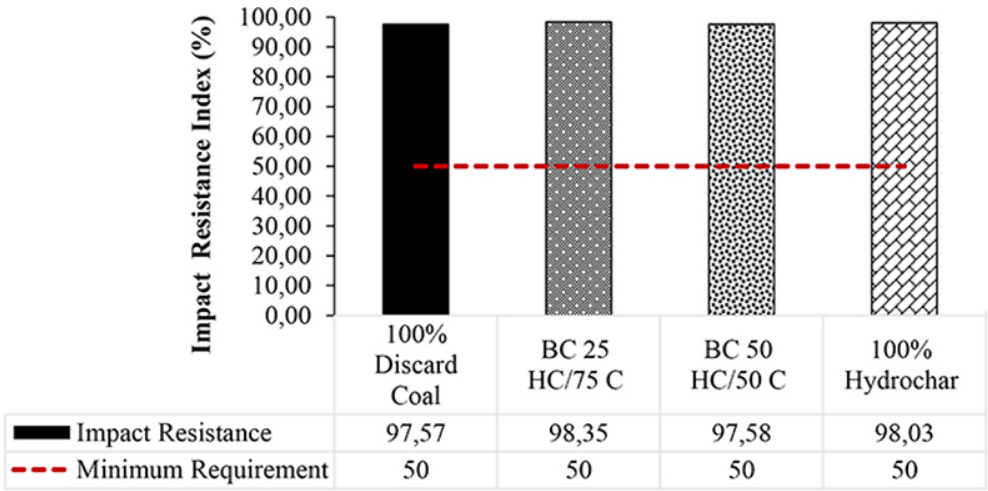

Figure 3-Effect of hydrochar inclusion on the impact resistance of pellets

for the 100\% hydrochar and 1.86\% MPa for the coal fines discard). On a pellet-to-pellet basis, the $2 \mathrm{~g}$ pellets outperformed the volume 'measured' pellets.

The high compressive strength obtained from the $\mathrm{BC}_{25 \mathrm{HC} / 75 \mathrm{C}}$ is considered to be the result of the interaction between the lignin content of the hydrochar (natural binder) and the minerals (35\% ash) and organic matter (35\% fixed carbon) components present in the high-ash discard fine coal utilized. In addition, fine coals are usually high in vitrinite and liberated fine clays. This attribute could aid in the softening and fusing of the hydrochar (more in $\mathrm{BC}_{25 \mathrm{HC} / 75 \mathrm{C}}$ ) supported by the minerals (ash) to create a strong pellet.

From these results it will be noted that all the samples tested clearly meet the standard compressive strength ( $0.38 \mathrm{MPa}$ ) required for pellet storage and handling. Although fuel with a higher ash content is not desirable for electricity generation, the results from the study suggest that for pellets with the highest compressive strength, a relatively high proportion of coal discard fines is required.

\section{Effect of hydrochar inclusion on impact resistance of pellets}

The drop durability test conducted in this study utilizes a similar method to that described by Kambo and Dutta, (2014). The samples were dropped from a height of $1.0 \mathrm{~m}$ onto a steel plate and the impact resistance index (IRI) determined using Equation [2]. The impact resistance durability (IRD) of all the pellets was over $97 \%$, with the $100 \%$ hydrochar pellet reported to be $98.03 \%$ and the $\mathrm{BC}_{25 \mathrm{HC} / 75 \mathrm{C}}$ pellet slightly higher (98.35\%). The results for the discard coal and sample $\mathrm{BC}_{50 \mathrm{HC} / 50 \mathrm{C}}$ were only marginally lower (both 97.5\%). The similarity of the durability results for all samples indicates that all samples meet the acceptable standard for storing and handling pellets.

\section{Effect of hydrochar inclusion on moisture resistance of pellets}

The water-resistance index (WRI) is proportional to the moisture uptake by a pellet, with lower quantities of water being absorbed leading to higher WRI values. In the current investigation, the quantities of water absorbed by the pellets after immersion in water for 30 minutes varied significantly, ranging from $11.13 \%$ to $31.53 \%$ as shown in Figure 4. None of the samples met the WRI standard of $95 \%$.

In the current investigation, sample $\mathrm{BC}_{25 \mathrm{HC} / 75 \mathrm{C}}$ absorbed the least amount of water at $11.13 \%$ and, by extension, recorded the highest WRI of $88.87 \%$ of the four samples tested. It was also observed that the $100 \%$ discard coal pellets and the $\mathrm{BC}_{50 \mathrm{HC} / 5 \mathrm{OC}}$ samples both exhibited similar and relatively higher water uptakes (14\%) with marginally lower WRIs (85\%), whereas the $100 \%$ hydrochar absorbed much more moisture (31\%) and had the lowest WRI (68\%). This sample exhibited the highest level of disintegration relative to the other three samples.

These results present an interesting phenomenon in that despite none of the samples meeting the WRI criterion, the presence of coal discard fines in the $100 \%$ discard and in both biochar-coal blend samples reduced the water uptake to a significant degree while also increasing the resistance to disintegration to an equally notable level, i.e., all three- samples that contained discard coal presented relatively high WRI values of over $85 \%$. A possible reason for the high moisture uptake and level of disintegration in the $100 \%$ hydrochar pellets lies in the potential level of porosity in the carbon structure of that material. 


\section{Effects of Searsia lancea hydrochar inclusion on the mechanical properties}

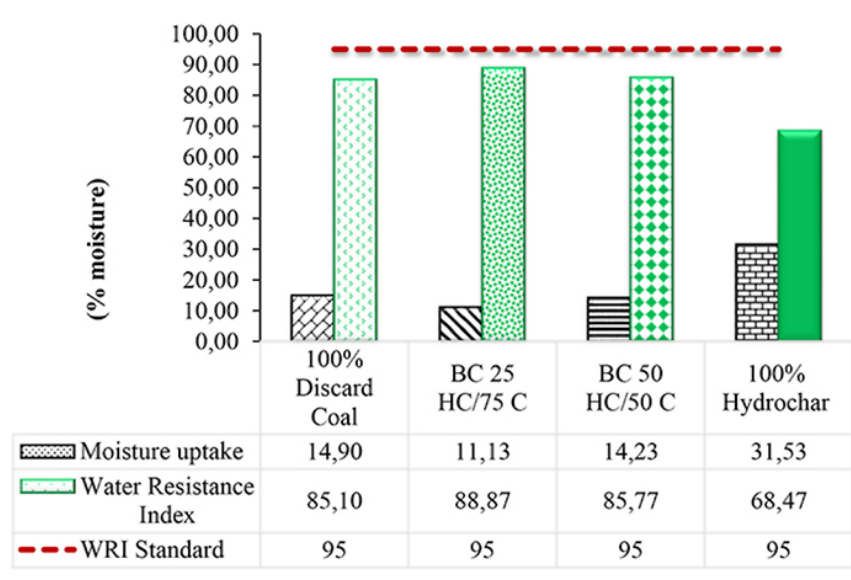

Figure 4-Effect of hydrochar inclusion on the water resistance index of pellets

When blended with coal fines, it is likely that many of the pores and voids in the hydrochar would be filled by variety of ultrafine inorganic components (clays) in the coal sample. A further possible reason could be the fusion and/or agglomeration of mineral (ash)-hydrochar components together, thereby blocking pores and reducing the water intake. Investigation into such aspects is planned in future research.

\section{Conclusion}

The results of this investigation show that the hydrochar, as produced, is of higher quality (lower ash and higher calorific value) than the fine discard coal. It has also been shown to possess an acceptably strong binding capacity, capable of creating pellets when mixed with coal fines that possess characteristics eminently suitable for use in power generation.

Biocoal pellets with a $75 \%$ coal blend displayed better mechanical, physical, disintegration resistance, and water uptake properties than the other three forms of pellets. Furthermore, pellets of this blend also possessed chemico-physical properties and calorific values indicating that they would be an acceptable substitute fuel for Eskom coal-fired power stations using coals with ash contents ranging from 34 to $42 \%$.

In comparison to other grades of coal products currently being sold in the South Africa marketplace (local grades B to D), the $\mathrm{BC}_{50 \mathrm{HC} / 50 \mathrm{C}}$ pellet is shown to be of equal or superior quality (Grade C). Pure hydrochar pellets are classified as Grade A in terms of calorific value and ash content.

In summary, this research has led to the production of a new biomass- and coal-based solid fuel suitable for heat and power generation, with the added advantages of:

- Lower $\mathrm{CO}_{2}$ emissions

- A use for fine discard coal, for which no practical, economic, or feasible method of utilization has been found to date

> The opportunity to develop new skills and employment opportunities in the cultivation and manufacture of such products for those employed across the coal and fuel production and power generation value chain.

\section{Acknowledgement}

This work is based on research supported wholly by the National Research Foundation of South Africa's SARChI Clean Coal Technology Grant (Grant Number: 86421). Opinions, findings, and conclusions expressed are those of the authors and are not necessarily to be attributed to the NRF. The authors also recognize the Eskom Tertiary Education Support Programme (financial support).

\section{References}

BADA, S.O., FALCON, R.M.S., FALCON, L.M., and BERGMANn, C.P. 2016. Co-firing potential of raw and thermally treated Phyllostachys aurea bamboo with coal. Energy Sources, Part A: Recovery, Utilization, and Environmental Effects, vol. 38, no. 10. pp. $1345^{-1354}$

Bada, S.O., Makwarela, M.O., Falcon, R.M.S., Falcon, L.M., and Sutton, A. 2018. Grindability and combustion behavior of raw and thermally treated different ages of Bambusa balcooa. Environmental Progress \& Sustainable Energy, vol 37, no. 6. pp. $1865^{-2176}$.

Department of EnERGy. 2018. Integrated Resource Plan 2018. http://www. energy.gov.za/IRP/irp-update-draftreport2018/IRP-Update-2018-Draft-forComments.pdf

EIA. 2016. Comparison with Other Projections : CP3: Total Energy Consumption, Annual Energy Outlook, 2016 CP-3-CP-5. Technical Report. 35. US Energy Information Administration, Office of Energy Analysis, US Department of Energy, Washington, DC.

GAQA, S. and WatTS, P. 2018. The agglomeration of coal fines using wet microalgae biomass. Journal of Energy in Southern Africa, vol. 29, no. 2. pp. 43-50.

KERINA, I. and BADA, S.O. 2020. The co-combustion performance and reaction kinetics of refuse derived fuels with South African high ash coal. Heliyon, vol. 6, no. 1.: e03309. doi: 10.1016/j.heliyon.2020.e03309

Kaliyan, N. and Vance Morey, R. 2009. Factors affecting strength and durability of densified biomass products. Biomass and Bioenergy, vol. 33, no. 3. pp. 337-359.

KAMBo, H.S. and DutTA, A. 2014. Strength, storage, and combustion characteristics of densified lignocellulosic biomass produced via torrefaction and hydrothermal carbonization. Applied Energy, vol. 135. pp. 182-191.

Kudo, S., Aska, M., Ryosuke, S., Fusa, M.K., Seiji, N., Yusuke, D., Koyo, N., and Jun-ICHIRO, H. 2014. Preparation of coke from hydrothermally treated biomass in sequence of hot briquetting and carbonization. ISIJ International, vol. 54, no. 11. pp. 2461-2469.

Ndou, N.R., BADA, S.O., FAlcon, R.M.S., and Weiersbye,. I.M. 2020. Co-combustion of Searsia lancea and Tamarix usneoides with high ash coal. Fuel, vol. 267: 117282.

RichaRdS, S.R. 1990. Physical testing of fuel briquettes. Fuel Processing Technology, vol. 25 , no. 2. pp. 89-100.

Rousset, P., Aguiar, C., Labbé, N., and Commandré, J.-M. 2011. Enhancing the combustible properties of bamboo by torrefaction. Bioresource Technology, vol. 102, no. 17. pp. 8225-8231.

SABA, A., SAHA, P., and REZA, M.T. 2017. Co-hydrothermal carbonization of coal-biomass blend: Influence of temperature on solid fuel properties. Fuel Processing Technology, vol. 167. pp. 711-720.

Setsepu, R.L., Abdulsalam, J. Weiersbye, I.M., and Bada, S.O. 2021. Hydrothermal carbonization of Searsia lancea trees grown on mine drainage: Processing variables and product composition. ACS Omega, vol. 6, no. 31. pp. 2029220302. https://dx.doi.org/10.1021/ acsomega.1c02173

Teixeira, P., Lopes, H., Gulyurtlu, I., Lapa, N., and Abelha, P. 2012. Evaluation of slagging and fouling tendency during biomass co-firing with coal in a fluidized bed. Biomass and Bioenergy, vol. 39. pp. 192-203.

WeIERSBYe, I.M. and Witkowski, E.T.F. 2007. Impacts of acid mine drainage on the regeneration potential of highveld phreatophytes. Multiple Use Management of Natural Forests and Woodlands: Policy Refinements and Scientific Progress IV. Department of Water Affairs and Forestry, Pretoria. pp. 224-237.

Zhu, Y., Si, Y., Wang, X., Zhang, W., Shao, J., Yang, H., and Chen, H. 2018. Characterization of hydrochar pellets from hydrothermal carbonization of agricultural residues. Energy \& Fuels, vol. 32, no. 11. pp. 11538-11546. 